\title{
Identification of cellular interaction partners of the influenza virus ribonucleoprotein complex and polymerase complex using proteomic-based approaches
}

\author{
Daniel Mayer $^{1, \#}$, Kaaweh Molawi ${ }^{1,2, \#, ~ L u i s ~ M a r t i ́ n e z-S o b r i d o ~}{ }^{2}$, Alexander Ghanem $^{1}$, Stefan \\ Thomas $^{1}$, Sacha Baginsky ${ }^{3}$, Jonas Grossmann ${ }^{3}$, Adolfo García-Sastre ${ }^{2}$, and Martin \\ Schwemmle ${ }^{1, *}$
}

${ }^{1}$ Department of Virology, Institute for Medical Microbiology and Hygiene, University of Freiburg, Germany 2 Department of Microbiology, Box 1124, Mount Sinai School of Medicine, 1 Gustave L Levy Place, New York, NY 100293 Institute of Plant Sciences, Swiss Federal Institute of Technology. ETH Zentrum, LFW E, CH-8092 Zurich, Switzerland

\section{Summary}

Cellular factors which associate with the influenza A viral ribonucleoprotein (vRNP) are presumed to play important roles in the viral life cycle. To date, interaction screens using individual vRNP components, such as the nucleoprotein or viral polymerase subunits, have revealed few cellular interaction partners. To improve this situation, we performed comprehensive, proteomics-based screens to identify cellular factors associated with the native vRNP and viral polymerase complexes. Reconstituted vRNPs were purified from human cells using Strep-tagged viral nucleoprotein (NPStrep) as bait, and co-purified cellular factors were identified by mass spectrometry (MS). In parallel, reconstituted native influenza A polymerase complexes were isolated using tandem affinity purification (TAP)-tagged polymerase subunits as bait, and co-purified cellular factors were again identified by MS. Using these techniques, we identified 41 proteins which co-purified with NP-Strepenriched vRNPs, and 4 cellular proteins which co-purified with the viral polymerase complex. Two of the polymerase-associated factors, importin- $\beta 3$ and PARP- 1 , represent novel interaction partners. Most cellular proteins previously shown to interact with either viral NP and/or vRNP were also identified using our method, demonstrating its sensitivity. Co-immunoprecipitation studies in virusinfected cells using selected novel interaction partners, including nucleophosmin (NPM), confirmed their association with vRNP. Immunofluorescence analysis further revealed that NPM is recruited to sites of viral transcription and replication in infected cells. Additionally, overexpression of NPM resulted in increased viral polymerase activity, indicating its role in viral RNA synthesis. In summary, the proteomics-based approaches used in this study represent powerful tools to identify novel vRNPassociated cellular factors for further characterization.

\section{Introduction}

The genome of influenza A virus is composed of eight segments of single-stranded RNA of negative polarity (vRNAs). The viral RNA segments exist as ribonucleoprotein (vRNP) with nucleoprotein (NP) and the viral RNA dependent RNA polymerase. ${ }^{1}$ The polymerase itself consists of the three subunits PB1, PB2 and PA. ${ }^{1}$ After infection, vRNPs are transported into

*Correspondence to: Dr. Martin Schwemmle, Department of Virology, University of Freiburg, Hermann-Herder-Strasse 11, D-79104 Freiburg, Germany, Phone: +49-761-203-6526, Fax: +49-761-203-6639, e-mail: martin.schwemmle @ uniklinik-freiburg.de.

\# contributed equally 
the nucleus where viral transcription and the replication of the viral genome take place. ${ }^{1}$ The untranslated sequences at the $5^{\prime}$ and the $3^{\prime}$ end of each genomic RNA segment act as promoter elements which are recognized by the viral polymerase. Initiation of transcription of viral mRNA requires a 5 'capped primer. ${ }^{2}$ The PB2 subunit of the polymerase has a cap-binding function and together with the PB1 subunit, which harbors an endonuclease function, is involved in the generation of the 5'capped primer from host pre-mRNA. The role of PA in the process of transcription is still unknown. The mRNA is elongated until the polymerase reaches a uridine rich sequence at the $5^{\prime}$ end of the vRNA. This sequence serves as a termination and polyadenylation signal. ${ }^{1}$ The soluble virus proteins are translated by free ribosomes in the cytoplasm and subsequently accumulate in the nucleus. This accumulation of viral proteins in the nucleus is thought to be responsible for the switch from viral transcription to viral genome replication. vRNA is also copied in a primer-independent manner into complementary (uncapped, non-polyadenylated) cRNA, which in turn becomes encapsidated by the NP and serves as a template for the novo synthesis of vRNAs. vRNAs assemble with NP, PB1, PB2 and PA to form vRNPs which bind to the viral matrix protein. The viral matrix protein M1 is thought to mediate the binding of the viral nuclear export protein (NEP) to vRNPs, thereby initiating a crm-1-dependent exit of the vRNP from the nucleus ${ }^{3}$ vRNPs are guided to the plasma membrane where they assemble with the cytoplasmic parts of the viral membrane proteins. This assembly is apparently mediated by the M1 protein which has also been hypothesized to be the driving force in the budding process. 4

The various functions of vRNP during the viral life cycle suggest that many cellular factors associate to this complex, fulfilling different functions. In addition, the interaction of vRNP components with cellular proteins may also determine the host specificity of influenza virus. However, to date only few cellular factors have been described which interact with these components. These include importin- $\alpha 2$, which recognizes unconventional nuclear localization signals of $\mathrm{NP}^{5}$, thereby mediating the nuclear import of vRNPs and NP. ${ }^{6}$ Biochemical purification studies also revealed the RNA helicase $\mathrm{BAT}^{7}$ as a factor that specifically interacts with monomeric NP. It is believed that this interaction stimulates the association of NP to viral RNA, thus promoting viral RNA synthesis. ${ }^{7}$ Similarly, binding of heat shock protein 90 (HSP90) to PB2 stimulates the viral polymerase activity. ${ }^{8}$ The large subunit of the host cell polymerase II represents another influenza polymerase-interacting factor. ${ }^{9}$ Although the functional significance of this interaction remains to be shown, it is believed that this interaction triggers premature polymerase II termination. ${ }^{10}$ The inducible heat shock protein 70 was shown to block nuclear export of vRNP by binding to this complex, ${ }^{11}$ whereas the role of the PA-interacting protein hCLE, a protein of unknown function, remains unclear. ${ }^{12}$ Finally, it is believed that the interaction of NP with the cytoskeleton component F-actin causes retention of vRNPs in the cytoplasm and prevents their re-import into the nucleus. ${ }^{13}$

The majority of the above described cellular factors were identified by either yeast-two-hybrid screens with individual components of vRNP, including polymerase subunits, or coimmunoprecipitation experiments using antibodies directed against a suspected cellular interaction partner. $5,8,9,12,13$ It is therefore reasonable to assume that not all interaction partners have been identified, especially those proteins interacting with native vRNPs or polymerase complexes. To identify cellular factors associated to these native viral complexes we purified reconstituted vRNPs by Strep-tagged viral nucleoprotein (NP-Strep) and the viral polymerase by tandem-affinity-purification (TAP)-tagged polymerase subunits from human cells and analyzed the co-purified cellular factors by mass spectrometry (MS). These analyses revealed the identification of 41 cellular proteins, including 5 of the 7 previously described interaction partners. Four cellular proteins were found to co-purify with the viral polymerase complex, two of which, importin- $\beta 3$ and the poly-adenyl-ribosyl-polymerase (PARP-1), represent new interaction partners. Co-immunoprecipitation studies confirmed the association of selected interaction partners to vRNP in virus-infected cells. Functional studies with a newly 
identified factor, nucleophosmin (NPM), revealed that this protein is not only recruited to the sites where viral replication and transcription occurs but also increases the viral polymerase activity. These data demonstrate that the proteomic-based approaches used in this study represent powerful tools to identify novel cellular factors of vRNPs and the polymerase complex for further functional characterization.

\section{Experimental procedure}

\section{Cells and viruses}

HEK293T, MDCK and Vero cells were grown in Dulbecco's modified essential medium high glucose (DMEM, Invitrogen) supplemented with $10 \%$ fetal calf serum, $2 \mathrm{mM} \mathrm{L}$-glutamine and penicilline/streptomycine. The mouse adapted Influenza A/WSN/33 (WSN) virus (H1N1) was propagated in MDCK cells.

\section{Plasmid construction}

The pCAGGS (pCA) ${ }^{14}$ based plasmids encoding PB1, PA, PB2 and NP (WSN strain) are described. ${ }^{15}$ The dual reporter plasmid pPOLI-FLUA-FF/SV40 Renilla contains the firefly luciferase gene flanked by the influenza A virus NS gene non-coding regions and a truncated POLI promoter and the hepatitis delta virus ribozyme, as well as the renilla luciferase under the control of the SV40 promoter. This plasmid expresses an influenza virus-like vRNA encoding firefly luciferase and a mRNA encoding renilla luciferase. In order to construct this plasmid, the firefly luciferase gene flanked by the NS gene non-coding regions was first inserted into the SapI site of the pPOLI vector, ${ }^{15}$ and subsequently a BamHI/BglII fragment derived from pRL-SV40 (Promega) was inserted into the BamHI site of pPOLI-FLUA-FF. Expression of firefly luciferase is only achieved upon cotransfection with plasmids encoding functional influenza A virus proteins PB2, PB1, PA and NP. Expression of renilla luciferase is used to monitor transfection efficiency. The reporter plasmid pPOLI-GFP was constructed by inserting the GFP ORF flanked by the non-coding regions of the NS gene of influenza A virus into the SapI site of the pPOLI vector. To obtain expression plasmids coding for Cterminal TAP-tagged bait proteins, the coding region of the TAP-tag was first amplified by PCR from plasmids coding for C-terminal tags harboring the calmodulin binding domain, 2 or 4 tobacco etch virus (TEV) protease cleavage sites and 2 protein A units ${ }^{16}$ and cloned into the SphI and XhoI sites of pCAGGS. ${ }^{14}$ Subsequently, the coding region of PA, PB1, PB2 were PCR amplified and cloned into the EcoRI and the SmaI site of pCAGGS-TAP with 2 TEV sites. The same was done for NP and pCAGGS-TAP with 4 TEV sites. Similarly, PB1, DDB1 and NPM were cloned into pCAGGS where a HA-or a Flag-tag had been inserted between the SmaI and the XhoI sites. The pCA-NP-Strep construct was derived from the pCA-NP-TAP construct with 4 TEV sites. By digesting with MfeI and XhoI 2 TEV sites and the protein A units were removed and replaced with a linker coding for the Strep II tag. ${ }^{17}$ This resulted in a C-terminal tag of NP, including the Strep motif, coding for 72 amino acids $(8.2 \mathrm{kDa})$. The correct sequence of all constructs described above was verified by sequencing.

\section{Strep-purification}

Two $15 \mathrm{~cm}$ dishes of $80 \%$ confluent HEK 293T cells were transfected by the calcium phosphate method with $5 \mu \mathrm{g}$ of pCA-PA, pCA-PB1, pCA-PB2, pPolI-GFP, $4 \mu \mathrm{g}$ of pCA-NP and $1 \mu \mathrm{g}$ of pCA-NP-Strep each. If not otherwise stated all steps were done at $4^{\circ} \mathrm{C}$ or on ice. Twenty-four $\mathrm{h}$ after transfection, cells were washed with buffered saline phosphate (PBS) and harvested for the preparation of total cell extracts (TCE) as described. ${ }^{16}$ Briefly, cells were low speed centrifuged and resuspended in $6 \mathrm{ml}$ of a hypotonic buffer (10 mM Hepes $\mathrm{pH} 7,9,1.5 \mathrm{mM}$ $\mathrm{MgCl}, 10 \mathrm{mM} \mathrm{KCl}, 0,5 \mathrm{mM}$ DTT, $1 \%$ protease inhibitors Mix G (Serva, Heidelberg, Germany). After 5 strokes in a douncer, $2 \mathrm{ml}$ of a hypertonic buffer were added (50 mM Hepes $\mathrm{pH} 7,5$, 1,26 M K-Acetat, $1,5 \mathrm{mM} \mathrm{MgCl}, 0,5 \mathrm{mM}$ DTT, $1 \%$ protease inhibitors), and the cells were 
dounced at least 20 times, incubated for $20 \mathrm{~min}$ and then centrifuged at $16000 \mathrm{~g}$ for $15 \mathrm{~min}$. TCE was diluted with $8 \mathrm{ml}$ buffer dilution buffer (10 $\mathrm{mM}$ Hepes $\mathrm{pH} 7,9,1,5 \mathrm{mM} \mathrm{MgCl}, 10$ $\mathrm{mM} \mathrm{KCl}, 0,5 \mathrm{mM}$ DTT) and a final concentration of $0.1 \% \mathrm{NP} 40,15 \%$ glycerol and $25 \mathrm{u} / \mathrm{ml}$ benzonase was added and incubated for $1 \mathrm{~h}$. After equlibration of a Strep-Tactin column (Iba, Göttingen, Germany) with $1 \mathrm{ml}$ bed volume with an equivalent mixture of all 3 buffers mentioned above. TCE was applied to the column and purification was further performed according to the manufacturers' recommendations. Elution fractions of $500 \mu \mathrm{l}$ were pooled, precipitated by the trichloric acid method and size fractioned on a 4 to $20 \%$ denaturing SDSgel (Invitrogen). Bands were visualized with Sypro-Ruby staining (Molecular Probes), excised and trypsin digested as described. ${ }^{18}$ Purification of either influenza NS1 or Borna Disease Virus phosphoprotein P fused to a Strep II-tag from HEK293T cells was essentially carried out as described above.

\section{Tap-Purification}

Influenza polymerase subunits and TAP fusions proteins encoding pCAGGS vectors (total amount $15 \mu \mathrm{g}$ ) were transfected into HEK 293t cells in a $10 \mathrm{~cm}$ dish using Metafectene (Biontex) according to the manufacturers recommendations. $24 \mathrm{~h}$ after transfection cells were harvested and TAP purification was carried as described ${ }^{19}$ with modifications. Briefly, TCE was obtained by incubating the cells for $10 \mathrm{~min}$ with $900 \mathrm{ml}$ lysis buffer containing $25 \%$ glycerol, $50 \mathrm{mM}$ Tris $\mathrm{HCl} \mathrm{pH8.0,} \mathrm{0.5 \%} \mathrm{Nodinet} \mathrm{P} \mathrm{40,} 200 \mathrm{mM} \mathrm{NaCl}, 1 \mathrm{mM} \beta$-mercaptoethanol, $1 \mathrm{mM}$ PMSF and $1 \%$ protease inhibitors. After spinning down the cell debris at $16000 \mathrm{~g}$, TCE was diluted in $4,6 \mathrm{ml} 110 \mathrm{mM} \mathrm{NaCl}$ solution and incubated for $2 \mathrm{~h}$ at $16^{\circ} \mathrm{C}$ with $100 \mu \mathrm{l}$ packed IgG-beads, which had been washed $3 x$ in binding buffer (10 mMTris pH8, $1 \%$ Glycerol, $0,2 \%$ Nonidet P40, $150 \mathrm{mM} \mathrm{NaCl}, 1 \mathrm{mM}$ PMSF). The charged beads were washed $3 \times$ with binding buffer containing $0,1 \mathrm{mM}$ dithiothreitol (DTT). Subsequently, the bait proteins were released into the supernatant by cleavage with the auto protease resistant mutant of TEV 20 at $16^{\circ} \mathrm{C}$.

The recovered supernatant from the IgG beads was diluted with $4 \mathrm{ml}$ binding buffer containing $4 \mathrm{mM} \mathrm{CaCl}_{2}$ and $2 \mathrm{mM}$ imidazole. This mixture was rotated with $100 \mu \mathrm{l}$ of packed calmodulin binding beads (Stratagene) in a $0.8 \times 4$ Polyprep column (Bio Rad) at $16^{\circ} \mathrm{C}$. After washing with $5 \mathrm{ml}$ of binding buffer containing $4 \mathrm{mM} \mathrm{CaCl}_{2}$ and $2 \mathrm{mM}$ imidazole proteins were eluted with $4 \times 150 \mu$ lelution buffer (5 mM EGTA and $10 \mathrm{mM}$ Tris $\mathrm{pH} \mathrm{8.0)}$. The elution fractions were treated as in the Strep-purification. For Fig. 1B the pooled and precipitated proteins were run on a denaturing $8 \%$ SDS-gel and the bands were visualized by silver staining.

\section{Mass Spectrometric Protein Identification}

Tryptic peptides of each fraction were resuspended in $5 \mu \mathrm{l}$ of $5 \%$ acetonitrile $(\mathrm{ACN})$ and $0.2 \%$ formic acid $(\mathrm{v} / \mathrm{v})$ in water, and loaded on laboratory-made silica capillary columns (inner diameter of $75 \mu \mathrm{m}$, length of $9 \mathrm{~cm}$; BGB Analytik AG, Bockten, Switzerland) packed with C18 reversed phase material (Magic C18 resins; $5 \mu \mathrm{m}, 200-\AA ̊$ pore; Michrom BioResources, Auburn, CA, USA). The peptide mixture was separated and eluted by a gradient from 5 to $65 \%$ $\mathrm{ACN}$ over $2 \mathrm{~h}$ followed by an increase up to $80 \%$ during an additional $15 \mathrm{~min}$. The flow rate at the tip of the column was adjusted to ca. $200 \mathrm{nl} / \mathrm{min}$. LC was coupled on line to an LCQDeca $\mathrm{XP}$ ion trap mass spectrometer (Thermo Finnigan, San Jose, CA, USA) equipped with a nanospray ionization source. Mass analysis was performed with a spray voltage of $2.0-2.5$ $\mathrm{kV}$ and one MS full scan followed by three data-dependent MS/MS scans of the three most intense parent ions. The dynamic exclusion function was enabled to allow two measurements of the same parent ion during $1 \mathrm{~min}$ followed by exclusion for $1 \mathrm{~min}$.

\section{Analysis and Interpretation of MS-data}

MS/MS data were interpreted according to the standards proposed by Carr and colleagues. ${ }^{21}$ The SEQUEST software (Thermo Finnigan) was used to search the NCBI non-redundant 
protein data base (www.ncbi.nlm.nih.gov, downloaded 06/13/2003). Data files were created by the SEQUEST software for every MS/MS scan with a total ion count of at least $5 \times 10^{4}$, minimal peak count of 35, and a precursor ion mass in the range of 300-2000 m/z. Data were searched against the data base restricted to tryptic peptides without modifications (except for carboxyamidomethylated cysteines 57.0513 and oxidized methionines 15.9994) allowing a parent mass error tolerance of $2 \mathrm{Da}$ and daughter ion error tolerance of $0.8 \mathrm{Da}$. To assess false positive identification rates statistically, we performed Peptide and Protein Prophet data analyses. $^{22,23}$ These statistical models allow for the assessment of false positive identification rates and we chose a cutoff of $>0.9$, for accepting protein identity suggesting a false positive identification rate of less than $10 \%$. To further decrease the likelihood of false positive protein identifications, we manually analyzed all spectra for correct peak assignment.

\section{Co-immunoprecipitation}

HEK 293 T cells were transfected in $35 \mathrm{~mm}$ dishes using Lipofectamin 2000 (Invitrogen). Approximately $48 \mathrm{~h}$ post transfection cells were washed with PBS and lysed in $500 \mu \mathrm{l}$ of lysis buffer (50 mM Tris (pH 8.0), 280 mM NaCl, 0.5\% NP-40, 0.2 mM EDTA, 2 mM EGTA, 10\% glycerol, $1 \mathrm{mM}$ DTT). After centrifugation at $10000 \mathrm{~g}$ for $15 \mathrm{~min}$., $250 \mu \mathrm{l}$ of whole cell extract were incubated rotating for $3 \mathrm{~h}$ at $4^{\circ} \mathrm{C}$ with $20 \mu \mathrm{l}$ of monoclonal $\alpha$-HA agarose beads (Sigma), which have been washed $3 \mathrm{x}$ with lysis buffer before use. For endogenous co-IP a confluent $10 \mathrm{~cm}$ dish of MDCK cells was infected with influenza A/WSN/33 (MOI 0,5) and $8 \mathrm{~h}$ post infection the cells were collected, washed with PBS and lysed in $1 \mathrm{ml}$ of lysis buffer $(50 \mathrm{mM}$ Tris- $\mathrm{HCl}$ (pH 8.0), $280 \mathrm{mM} \mathrm{NaCl}, 0.5 \%$ IPEGAL (or NP40), 0.2 mM EDTA, 2 mM EGTA, $10 \%$ Glycerol) supplemented with complete protease inhibitor cocktail (Roche). After centrifugation at $10000 \mathrm{~g}$ for $15 \mathrm{~min} .300 \mu \mathrm{l}$ of the supernatant (whole-cell-extract) was incubated with $2 \mu \mathrm{l}$ of polyclonal NP antibody for $2 \mathrm{~h}$ at $4^{\circ} \mathrm{C}$. After incubation with $30 \mu \mathrm{l}$ of protein A agarose beads for further $1 \mathrm{~h}$, beads were washed $5 \mathrm{x}$ with $1 \mathrm{ml}$ of lysis buffer. Samples were analyzed by western blotting using primary polyclonal antibody $(\mathrm{AB})$ against HA (Sigma, dilution 1:1000), Flag (Sigma, 1:1000), NP24 1:500), PB1 (kindly provided by P. Palese (Mount Sinai School of Medicine, NY), 1:250) as well as monoclonal AB against NPM (Chemicon, 1:2000) and DDB1 (Zymed, 1:500). Secondary antibodies included horseradish peroxidase-linked $\alpha$-rabbit IgG and $\alpha$-mouse IgG (both Amersham Biosciences, 1:5000), respectively.

\section{Immunofluorescence analysis}

MDCK cells were transfected in suspension using Lipofectamine 2000 (Invitrogen), plated in a 24 well dish containing glass cover slips and infected with WSN virus $24 \mathrm{~h}$ post transfection. Cells were fixed in 2,5\% paraformaldehyde in PBS for 30 minutes, washed once with PBS and permeabilized with PBS containing 0,5\% NP-40 for 30 min. After washing with PBS, cells were incubated with $1 \%$ bovine serum albumine (BSA) in PBS overnight at $4^{\circ} \mathrm{C}$ to block unspecific binding of antibodies. Next, the primary antibody-mix (polyclonal $\alpha$-NP 1:500; monoclonal $\alpha$-Flag 1:2000 (Chemicon) in PBS containing 1\% BSA was added for $1 \mathrm{~h}$ at RT. Cells were washed $3 x$ with PBS before the secondary antibody mixture (FITC linked $\alpha$-rabbit IgG 1:100 and Texas red linked $\alpha$-mouse IgG 1:100 in PBS containing 1\% BSA) was added for $30 \mathrm{~min}$. at RT. In a final step, cells were washed $3 \times$ with PBS, rinsed with water before mounting the cover slips on microscope slides.

\section{Minireplicon assays}

HEK 293T cells were transfected by Lipofectamine 2000 (Invitrogen) according to the manufacturer's instructions with expression plasmids encoding influenza virus proteins (pCAPB1, pCA-PB2, pCA-PA, pCA-NP, 50ng each), a reporter plasmid (50 ng) coding the firefly luciferase under the control of a Pol I promoter (to measure the influenza polymerase activity) 
and for renilla luciferase under the control of a SV40 promoter (for normalization). The activity of firefly and renilla luciferase was measured $48 \mathrm{~h}$ post transfection by using the Dual-luciferase reporter assay system (Promega) according to the manufacturer's instructions. To measure an effect of other proteins on the polymerase activity, cells were additionally transfected with empty plasmid or different amounts of a NPM-, DDB1- or GFP-expression plasmid (250/500/1000ng). All transfections contained the same amount of DNA to ensure that the transfection efficiency was the same in all wells. TAP-tagged polymerases were tested for functionality by replacing the corresponding expression plasmid coding for the untagged subunits with plasmids expressing the TAP-tagged polymerase subunit.

\section{Results and Discussion}

\section{Identification of cellular interaction partners of influenza virus RNP}

Cellular factors associated to influenza virus RNP are thought to play important roles in the viral life cycle. However, only few cellular interaction partners (CIP) had been previously identified, mainly by yeast-two-hybrid screens. To identify novel CIP by a proteomic-based approach, we purified reconstituted viral RNPs from human cells using a Strep-tagged viral nucleoprotein and identified the co-purified factors by MS. Initial attempts to purify vRNP components by TAP-tagged NP failed due to inefficient yields, although the tag itself did not impair the function of this protein (data not shown). Part of the TAP-tag was therefore replaced with a Strep-tag (see also experimental procedure). The Strep-tag is a small molecule ligand that specifically binds to strep-tactin, a derivate of streptavidin. ${ }^{17}$ HEK 293T cells were transfected with expression plasmids encoding the polymerase subunits (PA, PB1 and PB2), the viral nucleoprotein NP, an NP-Strep fusion protein and a plasmid transcribing an influenza virus minigenome RNA (Pol I-Minigenome) expressing the green fluorescence reporter protein (Fig. 1A). Since each vRNP contains many NP molecules, we transfected NP as well as StrepNP at a ratio of 5:1, to prevent tagged vRNPs from binding too tightly to the affinity matrix. Total cell extract was prepared 24 hours post transfection when successful replication and transcription of the reconstituted viral RNPs had occurred as indicated by strong intracellular GFP signals (data not shown). To allow purification of polymerase-associated factors the cell extract was treated with benzonase, a nonspecific nuclease that degrades DNA and RNA, as described by Engelhard et al. ${ }^{9}$ However, this treatment may partially attack the encapisdated viral minigenome RNA, ${ }^{25}$ and some cellular interaction partners that depend on the integrity of RNP-bound RNA might have been lost. Native NP-Strep complexes were isolated by a single-step purification using Strep-tactin columns and purified complexes were subjected to SDS-PAGE electrophoresis. As shown in Fig. 1A, the native NP-Strep protein complex released from these beads by desthiobiotin was composed of several proteins with different sizes. LC-MS/MS analysis revealed NP-Strep $(64.4 \mathrm{kDa})$ and NP $(56.2 \mathrm{kDa})$ to be the major protein bands purified (Fig. 1A). In addition, all polymerase subunits (PA, PB1 and PB2) were identified (Fig. 1A' supplemental Table 4). This suggests the successful purification of viral RNPs although the total amount of vRNP purified is difficult to judge, since it is impossible to differentiate between vRNP and other complexes such as NP/polymerase subunit complexes. 26, 27 After tryptic digestion of individual gel slices of the SDS-polyacrylamide gel shown in Fig. 1A and LC-MS/MS analysis, a total of 41 cellular proteins were identified (Table 1). The minority of these factors $(n=8)$ was identified by single hits, whereas the identity of the majority of co-purified proteins was based on independent peptide information (Table 1, supplemental Table 2). Most cellular factors previously shown to interact with either the viral nucleoprotein NP and/or vRNP, 5, 7, 11, 136, 28-30 including the spliceosome RNA helicase BAT1, HSP70, actin and Importin- $\alpha 2$ (Supplemental Table 1), were also identified in this experiment (Table 1), confirming the sensitivity of this method. However, the large subunit of the cellular polymerase II, which is suspected to bind to the vRNP via the viral polymerase complex, ${ }^{9}$ was not detected. To rule out the possibility that threshold levels of vRNP-bound polymerase II 
were insufficient for MS detection, we performed Western blot analysis using a phosphorylation-specific antibody recognizing multiple Ser-5-phosphorylated sites at the Cterminal domain (CTD) of this protein..$^{9}$ This confirmed the presence of this protein in the NPStrep-eluted fraction, whereas the Pol II CTD was not detected in control purifications using Strep-NS1 as bait (Supplemental Fig. 1).

The CIP identified (Table 1) can be separated into functional categories. These include components of the ubiquitination machinery, for example the ubiquitin carboxyl-terminal hydrolase 10 or the DNA-damage binding protein 1 (DDB1), as well as proteins involved in translation such as the ribosomal proteins of the $60 \mathrm{~S}$ and $40 \mathrm{~S}$ subunits, elongation factor $1 \alpha$ or tRNA synthetases. Furthermore, various heat shock proteins belong to the group of chaperones, while interleukin enhancer-binding factor 3 and transcription intermediary factor $1 \beta$ represent transcription factors. In addition, CIP such as actin and various isoforms of tubulin constitute members of the cellular cytoskeleton family.

Some CIP may represent components of larger cellular protein complexes. Thus, not only direct interactors might have been isolated by co-purification, but also proteins linked to the vRNP or NP complexes through bridging proteins. This could explain the identification of NPM and nucleolin (Table 1), which are known to form a complex in the nucleus. ${ }^{31}$ Furthermore, NPM binding may also account for the co-purification of ribosomal proteins, since this protein is associated with pre-ribosomal particles. ${ }^{32,33}$ It is also possible that some of the CIP, including the ribosomal proteins, the various isoforms of tubulin and heat shock proteins (Table 1), represent unspecific binding partners. However, we performed as controls purifications with N-terminally Strep-tagged Influenza NS1 or Borna disease virus phosphoprotein. In these assays, heat shock proteins were co-purified, but not ribosomal proteins nor tubulin (data not shown). This suggests that tubulin and ribosomal proteins represent specific CIP of influenza virus RNPs but still do not exclude the possibility that heat-shock proteins specifically interact with vRNPs.

Some of the CIP identified in this study are known to be recruited by other viruses, and this may therefore provide clues about their potential functions during influenza virus infection. For example, NPM is a multifunctional protein ${ }^{34}$ that was described to interact with HepatitisD virus (HDV) small and large antigen, thereby promoting viral transcription. ${ }^{35}$ It also interacts with HIV Rev protein and stimulates the nuclear import of this protein. ${ }^{36}$ The translation elongation factor $1 \alpha$ represents an essential co-factor of the viral polymerase of vesicular stomatitis virus (VSV). ${ }^{37}$ The DNA-damage binding protein 1 (DDB1) interacts with the viral protein $\mathrm{HBx}$ of Hepatitis B Virus (HBV) and this interaction is necessary to establish efficient viral replication, 38 possibly by preventing DDB 1 from binding to the promoter of the protein kinase $\mathrm{R}$ (PKR), thereby reducing the antiviral response of the host cell. ${ }^{39}$ Interestingly, another CIP of influenza virus RNP components, the heterogeneous nuclear ribonucleoprotein A1, cooperates with DDB1 in the regulation of the PKR promoter. Additionally, DDB1 has been shown to be a core subunit of the Cul4A-based ubiquitin ligase complex. ${ }^{40}$ To escape the innate immune system, the $\mathrm{V}$ proteins of several paramxyoviruses form a complex with DDB1 and STAT proteins (key signal transducers in the interferon pathway) to initiate their proteasomal degradation. ${ }^{41-43}$ Furthermore, Poly-adenyl-ribosyl-polymerase 1 (PARP-1) is a multifunctional protein participating in the regulation of both DNA repair and transcription. ${ }^{44}$ Recognition of DNA single strand breaks activates PARP- 1 to synthesize polymers of ADPribose and transfer them to itself and to specific acceptor proteins for DNA repair. ${ }^{44}$ However, PARP-1 is also known to influence host gene transcription by modification of topoisomerases, transcription factors, $\mathrm{p} 53$ and other proteins. ${ }^{44}$ In addition, PARP- 1 is a negative regulator of HIV-1 viral transcription. ${ }^{45}$ Although there is no immediate link explaining a possible function of PARP-1 during influenza virus infection, infection of primary cells lacking PARP-1 resulted in 20-fold decreased virus titers as compared to wild-type cells (Mayer, M., Hassa, P., Hottiger, 
M. and Schwemmle, M., unpublished), suggesting that this protein contributes to viral replication. Further studies will be needed to investigate the role of CIPs of the influenza virus RNPs in viral replication.

\section{Identification of cellular interaction partners of the influenza virus polymerase complex}

To isolate cellular factors that bind to the trimeric polymerase complex only, we expressed two untagged and one C-terminally TAP-tagged polymerase subunits in 293T cells as described in Fig. 1B and purified the complex by the TAP-method. ${ }^{9}$ The activity of the TAP-tagged fusion proteins was comparable to unmodified polymerase subunits when assayed in an influenza virus minireplicon system (data not shown). MS analysis revealed that purification of the polymerase complex using PA-TAP as bait resulted in the co-purification of the two untagged polymerase subunits (Fig. 1B, lane 3), in addition to HSP90 (Fig. 1B, lane 3, Table 2, Supplemental Table 3), a previously described factor known to interact with the PB2 polymerase subunit ${ }^{8}$ (Supplemental Table 1). Furthermore, MS analysis identified importin$\beta 3$ and PARP-1 as components of the silver-stained band at approximately $120 \mathrm{kDa}$ (Fig. 1B, lane 3). Moreover, importin- $\beta 3$ and PARP- 1 were not co-purified when all three polymerase subunits were expressed without the TAP-tag (Fig. 1B, lane 1), demonstrating the specific copurification of both proteins. In addition, expression of PA-TAP alone failed to co-purify these two factors (Fig. 1B, lane 2). Similar to the NP-Strep-purification, the presence of the large subunit of the cellular polymerase II was not detectable by MS. However, using the highly sensitive phosphorylation-specific antibody recognizing the multiple Ser-5-phosphorylated sites of this protein, we could again confirm the presence of this protein by Western blot analysis (data not shown). Unfortunately, accompanying unspecific cellular proteins with molecular masses of $<50000$ which were purified by the TAP procedure, independently of the presence of bait proteins (Fig. 1B), prevented the identification of specific low molecular weight CIP.

Importin- $\beta 3$ represents a novel CIP which co-purified with the polymerase complex only. This protein recognizes and initiates nuclear translocation of its substrate by direct binding and without the need of additional import factors. ${ }^{46}$ Since the assembly of the polymerase subunits occurs in the nucleus and is independent on the presence of the viral nucleoprotein, it seems likely that the nuclear import of either PB2 or the complex consisting of PA and PB1 that is preformed in the cytoplasm 47 is mediated by importin- $\beta 3$. Since importin- $\beta 3$ binds to the TAPpurified PB1/PA complex (data not shown) but not to PA-TAP (Fig. 1B), we speculate that importin- $\beta 3$ recognizes $\mathrm{PB} 1$ and thereby promotes the nuclear import of PB1/PA complex. Importin- $\beta 3$ was not found to be associated with vRNP (Table 1), most likely because it is released after transport of its cargo to the nucleus, and thus prior to polymerase binding to the vRNP. In addition to importin- $\beta 3$, we also identified PARP- 1 as a new CIP of the polymerase complex. Notably, this nuclear factor was identified with both purification strategies (Fig. 1A and B), indicating that PARP- 1 , in contrast to importin- $\beta 3$, is also associated with the RNPbound polymerase complex.

In summary, purification of the viral polymerase complex identified 4 CIP, including two new (Importin- $\beta 3$ and PARP-1) and two known factors. Co-purification of the two previously described factors, the large subunit of polymerase II and the PB2-interacting protein HSP90, further demonstrated the feasibility of this purification method to identify CIP of the viral polymerase. hCLE, a protein of unknown function, described to interact with the PA subunit ${ }^{12}$ was not identified in our study. This might be due to a protein concentration below the limit necessary for detection by MS analysis or loss during the purification procedure.

\section{The cellular proteins NPM and DDB1 specifically associate with the viral RNP}

We selected two vRNP-interacting proteins, DDB1 and NPM (Table 1), to confirm specific interaction by co-immunoprecipitation (co-IP) experiments, since we could not exclude the 
possibility that some CIP might represent unspecific factors. For this purpose we reconstituted the viral RNP in 293T cells by transfection of expression plasmids coding for the viral minigenome, NP, PB2, PA and the HA-tagged polymerase subunit PB1 (PB1-HA) together with C-terminally Flag-tagged DDB1 or NPM, respectively. After 24 hours a cell extract was prepared and the viral RNPs were immunoprecipitated by specific antibodies directed against the HA-tag of PB1-HA. This resulted not only in the co-precipitation of the viral nucleoprotein but also in the co-precipitation of DDB1-Flag (Fig. 2A, lane 3) or NPM-Flag (Fig. 2B, lane 3), indicating that both factors interact with reconstituted vRNPs. In control IPs, using untagged PB1 or no viral polymerase subunits neither DDB1 nor NPM were detected in the precipitates (Figs. 2A and 2B, lane 2). Next we wanted to demonstrate association of endogenous DDB1 and NPM with authentic viral RNPs. After infection of MDCK cells with WSN virus for 8 hours, a cell extract was prepared and vRNP were precipitated using NP-specific antibodies (Fig. 2C). Successful IP of the vRNP could be demonstrated by the presence of NP as well as the enrichment of PB1 (Fig. 2C, lower panels). In addition, both DDB1 and NPM were successfully co-immunoprecipiated, whereas in control IPs using mock-infected cells (Fig. 2, lane 3), no DDB1 or NPM was detectable. In summary these results indicate that DDB1 and NPM specifically associate with the viral RNP.

\section{NPM is relocated in virus-infected cell and promotes viral polymerase efficiency}

NPM is a major nucleolar protein involved in the ribosome biogenesis. Although NPM is found primarily in the nucleolus it has the ability to shuttle between the nucleus and cytoplasm. ${ }^{48}$ Since influenza virus replication and transcription occur in the nucleoplasm and not in the nucleolus, ${ }^{49}$ we wondered whether NPM might be relocated from the nucleolus to these sites. To test this hypothesis, we analyzed the sub-cellular localization of NPM during the course of an influenza virus infection. Since no suitable NPM-specific antibodies were available to detect endogenous NPM by IFA, we first transfected MDCK cells with NPM-Flag, then infected these cells 12 hours later with influenza virus and performed IFA using Flag-tag- and NPspecific antibodies. As shown in Fig. 3A, early in infection (3 to 4 hours) NPM-Flag resides in the nucleolus ${ }^{35}$ whereas the majority of the viral nucleoprotein is found primarily in the nucleoplasm. In contrast, at later time points (6-8h) NPM-Flag was found in the nucleoplasm, partially co-localizing with the nucleoprotein (Fig. $3 \mathrm{~A}$ and B). These results indicated that NPM is recruited to the sites of the viral RNP. After 8 hours of infection the viral nucleoprotein is partially found in the cytoplasm as mature vRNPs are transported into the cytoplasm to become incorporated into virus particles. ${ }^{50}$ As shown in Fig. 3B, NPM was not detectable in the cytoplasm at an intermediate stage of infection, ${ }^{51}$ suggesting that this protein is only associated with the nuclear vRNPs during viral replication and transcription.

Since NPM is known to increase hepatitis delta virus (HDV) transcription by binding to the HDV antigens, 35 we speculated that over-expression of NPM might also increase the influenza virus polymerase activity. To test this, vRNPs were reconstituted in 293T cells using an influenza virus minigenome coding for the luciferase protein, which allows the quantification of the polymerase activity. Increasing concentrations of an NPM-expression plasmid resulted in enhanced polymerase activity, with a maximum two-fold increase (Fig. 4). In contrast, similar concentrations of GFP-expressing plasmids had no impact on the polymerase activity. NPM is known to possess chaperone activity in its $\mathrm{N}$-terminal region, whereas a nucleic acid binding domain was mapped to its $\mathrm{C}$-terminal region. ${ }^{52} \mathrm{It}$ is believed that the chaperone activity prevents protein aggregation of ribosomal proteins in the nucleolus and therefore facilitates the ribosome assembly process. ${ }^{52}$ Increasing concentrations of an expression plasmid coding for the N-terminal 134 aa of NPM (NPM $\Delta$ C134), harboring the chaperone activity, ${ }^{52}$ also resulted in an enhanced polymerase activity, with a maximum 4 -fold increased (Fig. 4). Similar to the function of BAT1, which also enhances viral RNA synthesis by facilitating NP-RNA interaction, we speculate that NPM might support correct assembly of 
vRNPs by its chaperone activity rather than having a direct effect on the vRNP-bound polymerase. However, NPM can also interfere with the activation of the interferon-induced protein kinase R (PKR), ${ }^{53}$ which is activated by double-stranded RNA ${ }^{53}$ and also reside in the nucleus 54,55 . Therefore, recruitment of NPM to the sites of viral replication and transcription, where dsRNA formation may occur, might prevent the activation of PKR in the nucleus resulting in increased viral transcription and replication.

\section{Conclusions}

Due to their lack of the complete components for sustaining independent life, viruses are necessarily dependent on their host cells for replication. While many efforts have been undertaken to identify single interactions between host and viral proteins, these methods have proven insufficient for uncovering larger numbers of these interactions. This work provides evidence that proteomics-based approaches are suitable tools to identify CIP of influenza virus RNP and its components. Co-purification of the majority of previously identified CIP further confirmed the specificity of these methods. Proof of principle that newly identified factors interact specifically was demonstrated by co-immunoprecipitations of two CIP associated to vRNPs from virus-infected cells. Finally, first functional studies indicate that one factor, NPM, promotes viral polymerase activity. It should be noted that it is also possible that some of the identified CIP represent negative regulators of influenza virus replication involved in host innate immune responses. Further experiments can now be designed aiming at the function of these proteins in the influenza virus life cycle.

Cellular factors that bind to vRNP or the polymerase complex may also represent important mediators of viral pathogenicity. Previous studies demonstrated that beyond the acquirement of a polybasic cleavage site in the viral hemagglutinin protein and the suppression of the innate immune system by the non-structural protein NS1,56, 57 enhanced viral polymerase activities of highly pathogenic avian influenza viruses of the H5N1 and H7N7 subtype facilitate high virulence and mediate host tropism in mammalian cells. ${ }^{58-60}$ Similarly, enhanced viral replication in human cells mediated by the viral polymerase appears to be responsible, at least in part, for the high virulence of the pandemic 1918 influenza virus. ${ }^{61}$ These findings suggest that optimized interactions of viral polymerase proteins with cellular host factors are molecular correlates of host adaptation and of pathogenicity. Proteomics-based approaches may therefore represent an excellent tool with which to identify and characterize such CIP in mammalian and avian cells, especially since the complete chicken genome was recently sequenced. ${ }^{62}$

\section{Supplementary Material}

Refer to Web version on PubMed Central for supplementary material.

\section{Acknowledgements}

We thank Richard Cádagan for excellent technical assistance Friedemann Weber and Geoffrey Chase for critical reading of the manuscript. This work was partially supported by NIH grants to A.G.-S and by DFG grant to MS. DM was supported by a grant of the Schweizerische Stiftung für medizinisch biologische Stipendien (SSMBS) through a donation by Novartis AG. KM was supported by the Studienstiftung des Deutschen Volkes.

\section{References}

1. Neumann G, Brownlee GG, Fodor E, Kawaoka Y. Orthomyxovirus replication, transcription, and polyadenylation. Curr Top Microbiol Immunol 2004;283:121-43. [PubMed: 15298169]

2. Krug RM. Priming of influenza viral RNA transcription by capped heterologous RNAs. Curr Top Microbiol Immunol 1981;93:125-49. [PubMed: 6269803]

3. O'Neill RE, Talon J, Palese P. The influenza virus NEP (NS2 protein) mediates the nuclear export of viral ribonucleoproteins. Embo J 1998;17(1):288-96. [PubMed: 9427762] 
4. Gomez-Puertas P, Albo C, Perez-Pastrana E, Vivo A, Portela A. Influenza virus matrix protein is the major driving force in virus budding. J Virol 2000;74(24):11538-47. [PubMed: 11090151]

5. Wang P, Palese P, O'Neill RE. The NPI-1/NPI-3 (karyopherin alpha) binding site on the influenza a virus nucleoprotein NP is a nonconventional nuclear localization signal. J Virol 1997;71(3):1850-6. [PubMed: 9032315]

6. Cros JF, Garcia-Sastre A, Palese P. An unconventional NLS is critical for the nuclear import of the influenza A virus nucleoprotein and ribonucleoprotein. Traffic 2005;6(3):205-13. [PubMed: 15702989]

7. Momose F, Basler CF, O'Neill RE, Iwamatsu A, Palese P, Nagata K. Cellular splicing factor RAF-2p48/NPI-5/BAT1/UAP56 interacts with the influenza virus nucleoprotein and enhances viral RNA synthesis. J Virol 2001;75(4):1899-908. [PubMed: 11160689]

8. Momose F, Naito T, Yano K, Sugimoto S, Morikawa Y, Nagata K. Identification of Hsp90 as a stimulatory host factor involved in influenza virus RNA synthesis. J Biol Chem 2002;277(47):4530614. [PubMed: 12226087]

9. Engelhardt OG, Smith M, Fodor E. Association of the influenza A virus RNA-dependent RNA polymerase with cellular RNA polymerase II. J Virol 2005;79(9):5812-8. [PubMed: 15827195]

10. Chan AY, Vreede FT, Smith M, Engelhardt OG, Fodor E. Influenza virus inhibits RNA polymerase II elongation. Virology 2006;351(1):210-7. [PubMed: 16624367]

11. Hirayama E, Atagi H, Hiraki A, Kim J. Heat shock protein 70 is related to thermal inhibition of nuclear export of the influenza virus ribonucleoprotein complex. J Virol 2004;78(3):1263-70. [PubMed: 14722281]

12. Huarte M, Sanz-Ezquerro JJ, Roncal F, Ortin J, Nieto A. PA subunit from influenza virus polymerase complex interacts with a cellular protein with homology to a family of transcriptional activators. $J$ Virol 2001;75(18):8597-604. [PubMed: 11507205]

13. Digard P, Elton D, Bishop K, Medcalf E, Weeds A, Pope B. Modulation of nuclear localization of the influenza virus nucleoprotein through interaction with actin filaments. J Virol 1999;73(3):222231. [PubMed: 9971805]

14. Niwa H, Yamamura K, Miyazaki J. Efficient selection for high-expression transfectants with a novel eukaryotic vector. Gene 1991;108(2):193-9. [PubMed: 1660837]

15. Schickli JH, Flandorfer A, Nakaya T, Martinez-Sobrido L, Garcia-Sastre A, Palese P. Plasmid-only rescue of influenza A virus vaccine candidates. Philos Trans R Soc Lond B Biol Sci 2001;356(1416): 1965-73. [PubMed: 11779399]

16. Mayer D, Baginsky S, Schwemmle M. Isolation of viral ribonucleoprotein complexes from infected cells by tandem affinity purification. Proteomics 2005;5(17):4483-7. [PubMed: 16206331]

17. Lichty JJ, Malecki JL, Agnew HD, Michelson-Horowitz DJ, Tan S. Comparison of affinity tags for protein purification. Protein Expr Purif 2005;41(1):98-105. [PubMed: 15802226]

18. Shevchenko A, Wilm M, Vorm O, Mann M. Mass spectrometric sequencing of proteins silver-stained polyacrylamide gels. Anal Chem 1996;68(5):850-8. [PubMed: 8779443]

19. Fodor E, Smith M. The PA subunit is required for efficient nuclear accumulation of the PB1 subunit of the influenza A virus RNA polymerase complex. J Virol 2004;78(17):9144-53. [PubMed: 15308710]

20. Kapust RB, Tozser J, Fox JD, Anderson DE, Cherry S, Copeland TD, Waugh DS. Tobacco etch virus protease: mechanism of autolysis and rational design of stable mutants with wild-type catalytic proficiency. Protein Eng 2001;14(12):993-1000. [PubMed: 11809930]

21. Carr S, Aebersold R, Baldwin M, Burlingame A, Clauser K, Nesvizhskii A. The need for guidelines in publication of peptide and protein identification data: Working Group on Publication Guidelines for Peptide and Protein Identification Data. Mol Cell Proteomics 2004;3(6):531-3. [PubMed: 15075378]

22. Keller A, Nesvizhskii AI, Kolker E, Aebersold R. Empirical statistical model to estimate the accuracy of peptide identifications made by MS/MS and database search. Anal Chem 2002;74(20):5383-92. [PubMed: 12403597]

23. Nesvizhskii AI, Keller A, Kolker E, Aebersold R. A statistical model for identifying proteins by tandem mass spectrometry. Anal Chem 2003;75(17):4646-58. [PubMed: 14632076] 
24. Bourmakina SV, Garcia-Sastre A. The morphology and composition of influenza A virus particles are not affected by low levels of M1 and M2 proteins in infected cells. J Virol 2005;79(12):792632. [PubMed: 15919950]

25. Yamanaka K, Ishihama A, Nagata K. Reconstitution of influenza virus RNA-nucleoprotein complexes structurally resembling native viral ribonucleoprotein cores. J Biol Chem 1990;265(19): 11151-5. [PubMed: 2358455]

26. Poole E, Elton D, Medcalf L, Digard P. Functional domains of the influenza A virus PB2 protein: identification of NP- and PB1-binding sites. Virology 2004;321(1):120-33. [PubMed: 15033571]

27. Biswas SK, Boutz PL, Nayak DP. Influenza virus nucleoprotein interacts with influenza virus polymerase proteins. J Virol 1998;72(7):5493-501. [PubMed: 9621005]

28. O'Neill RE, Palese P. NPI-1, the human homolog of SRP-1, interacts with influenza virus nucleoprotein. Virology 1995;206(1):116-25. [PubMed: 7831767]

29. Garcia-Robles I, Akarsu H, Muller CW, Ruigrok RW, Baudin F. Interaction of influenza virus proteins with nucleosomes. Virology 2005;332(1):329-36. [PubMed: 15661164]

30. Melen K, Fagerlund R, Franke J, Kohler M, Kinnunen L, Julkunen I. Importin alpha nuclear localization signal binding sites for STAT1, STAT2, and influenza A virus nucleoprotein. J Biol Chem 2003;278(30):28193-200. [PubMed: 12740372]

31. Li YP, Busch RK, Valdez BC, Busch H. C23 interacts with B23, a putative nucleolar-localizationsignal-binding protein. Eur J Biochem 1996;237(1):153-8. [PubMed: 8620867]

32. Olson MO, Wallace MO, Herrera AH, Marshall-Carlson L, Hunt RC. Preribosomal ribonucleoprotein particles are a major component of a nucleolar matrix fraction. Biochemistry 1986;25(2):484-91. [PubMed: 3955008]

33. Pinol-Roma S. Association of nonribosomal nucleolar proteins in ribonucleoprotein complexes during interphase and mitosis. Mol Biol Cell 1999;10(1):77-90. [PubMed: 9880328]

34. Ye K. Nucleophosmin/B23, a multifunctional protein that can regulate apoptosis. Cancer Biol Ther 2005;4(9):918-23. [PubMed: 16103750]

35. Huang WH, Yung BY, Syu WJ, Lee YH. The nucleolar phosphoprotein B23 interacts with hepatitis delta antigens and modulates the hepatitis delta virus RNA replication. J Biol Chem 2001;276(27): 25166-75. [PubMed: 11309377]

36. Fankhauser C, Izaurralde E, Adachi Y, Wingfield P, Laemmli UK. Specific complex of human immunodeficiency virus type $1 \mathrm{rev}$ and nucleolar B23 proteins: dissociation by the Rev response element. Mol Cell Biol 1991;11(5):2567-75. [PubMed: 2017166]

37. Das T, Mathur M, Gupta AK, Janssen GM, Banerjee AK. RNA polymerase of vesicular stomatitis virus specifically associates with translation elongation factor-1 alphabetagamma for its activity. Proc Natl Acad Sci U S A 1998;95(4):1449-54. [PubMed: 9465035]

38. Sitterlin D, Bergametti F, Transy C. UVDDB p127-binding modulates activities and intracellular distribution of hepatitis B virus X protein. Oncogene 2000;19(38):4417-26. [PubMed: 10980617]

39. Das S, Ward SV, Markle D, Samuel CE. DNA damage-binding proteins and heterogeneous nuclear ribonucleoprotein A1 function as constitutive KCS element components of the interferon-inducible RNA-dependent protein kinase promoter. J Biol Chem 2004;279(8):7313-21. [PubMed: 14645369]

40. Sugasawa K, Okuda Y, Saijo M, Nishi R, Matsuda N, Chu G, Mori T, Iwai S, Tanaka K, Hanaoka F. UV-induced ubiquitylation of XPC protein mediated by UV-DDB-ubiquitin ligase complex. Cell 2005;121(3):387-400. [PubMed: 15882621]

41. Didcock L, Young DF, Goodbourn S, Randall RE. The V protein of simian virus 5 inhibits interferon signalling by targeting STAT1 for proteasome-mediated degradation. J Virol 1999;73(12):9928-33. [PubMed: 10559305]

42. Ulane CM, Horvath CM. Paramyxoviruses SV5 and HPIV2 assemble STAT protein ubiquitin ligase complexes from cellular components. Virology 2002;304(2):160-6. [PubMed: 12504558]

43. Precious B, Childs K, Fitzpatrick-Swallow V, Goodbourn S, Randall RE. Simian virus 5 V protein acts as an adaptor, linking DDB1 to STAT2, to facilitate the ubiquitination of STAT1. J Virol 2005;79 (21):13434-41. [PubMed: 16227264]

44. Gagne JP, Hendzel MJ, Droit A, Poirier GG. The expanding role of poly(ADP-ribose) metabolism: current challenges and new perspectives. Curr Opin Cell Biol 2006;18(2):145-51. [PubMed: 16516457] 
45. Parent M, Yung TM, Rancourt A, Ho EL, Vispe S, Suzuki-Matsuda F, Uehara A, Wada T, Handa H, Satoh MS. Poly(ADP-ribose) polymerase-1 is a negative regulator of HIV-1 transcription through competitive binding to TAR RNA with Tat.positive transcription elongation factor $\mathrm{b}$ ( $\mathrm{p}$-TEFb) complex. J Biol Chem 2005;280(1):448-57. [PubMed: 15498776]

46. Jakel S, Mingot JM, Schwarzmaier P, Hartmann E, Gorlich D. Importins fulfil a dual function as nuclear import receptors and cytoplasmic chaperones for exposed basic domains. Embo J 2002;21 (3):377-86. [PubMed: 11823430]

47. Deng T, Sharps J, Fodor E, Brownlee GG. In vitro assembly of PB2 with a PB1-PA dimer supports a new model of assembly of influenza A virus polymerase subunits into a functional trimeric complex. J Virol 2005;79(13):8669-74. [PubMed: 15956611]

48. Borer RA, Lehner CF, Eppenberger HM, Nigg EA. Major nucleolar proteins shuttle between nucleus and cytoplasm. Cell 1989;56(3):379-90. [PubMed: 2914325]

49. Amorim MJ, Digard P. Influenza A virus and the cell nucleus. Vaccine. 2006

50. Pleschka S, Wolff T, Ehrhardt C, Hobom G, Planz O, Rapp UR, Ludwig S. Influenza virus propagation is impaired by inhibition of the Raf/MEK/ERK signalling cascade. Nat Cell Biol 2001;3(3):301-5. [PubMed: 11231581]

51. Elton D, Amorim MJ, Medcalf E, Digard P. 'Genome gating'; polarized intranuclear trafficking of inlfuneza virus RNPs. Biology Letters 2005;1:113-117. [PubMed: 17148142]

52. Hingorani K, Szebeni A, Olson MO. Mapping the functional domains of nucleolar protein B23. J Biol Chem 2000;275(32):24451-7. [PubMed: 10829026]

53. Pang Q, Christianson TA, Koretsky T, Carlson H, David L, Keeble W, Faulkner GR, Speckhart A, Bagby GC. Nucleophosmin interacts with and inhibits the catalytic function of eukaryotic initiation factor 2 kinase PKR. J Biol Chem 2003;278(43):41709-17. [PubMed: 12882984]

54. Jeffrey IW, Kadereit S, Meurs EF, Metzger T, Bachmann M, Schwemmle M, Hovanessian AG, Clemens MJ. Nuclear localization of the interferon-inducible protein kinase PKR in human cells and transfected mouse cells. Exp Cell Res 1995;218(1):17-27. [PubMed: 7737357]

55. Besse S, Rebouillat D, Marie I, Puvion-Dutilleul F, Hovanessian AG. Ultrastructural localization of interferon-inducible double-stranded RNA-activated enzymes in human cells. Exp Cell Res 1998;239 (2):379-92. [PubMed: 9521856]

56. Parrish CR, Kawaoka Y. The origins of new pandemic viruses: the acquisition of new host ranges by canine parvovirus and influenza A viruses. Annu Rev Microbiol 2005;59:553-86. [PubMed: 16153179]

57. Neumann G, Kawaoka Y. Host range restriction and pathogenicity in the context of influenza pandemic. Emerg Infect Dis 2006;12(6):881-6. [PubMed: 16707041]

58. Gabriel G, Dauber B, Wolff T, Planz O, Klenk HD, Stech J. The viral polymerase mediates adaptation of an avian influenza virus to a mammalian host. Proc Natl Acad Sci U S A 2005;102(51):18590-5. [PubMed: 16339318]

59. Salomon R, Franks J, Govorkova EA, Ilyushina NA, Yen HL, Hulse-Post DJ, Humberd J, Trichet M, Rehg JE, Webby RJ, Webster RG, Hoffmann E. The polymerase complex genes contribute to the high virulence of the human H5N1 influenza virus isolate A/Vietnam/1203/04. J Exp Med 2006;203 (3):689-97. [PubMed: 16533883]

60. Hatta M, Gao P, Halfmann P, Kawaoka Y. Molecular basis for high virulence of Hong Kong H5N1 influenza A viruses. Science 2001;293(5536):1840-2. [PubMed: 11546875]

61. Tumpey TM, Basler CF, Aguilar PV, Zeng H, Solorzano A, Swayne DE, Cox NJ, Katz JM, Taubenberger JK, Palese P, Garcia-Sastre A. Characterization of the reconstructed 1918 Spanish influenza pandemic virus. Science 2005;310(5745):77-80. [PubMed: 16210530]

62. Hillier LW, Miller W, Birney E, Warren W, Hardison RC, Ponting CP, Bork P, Burt DW, Groenen MA, Delany ME, Dodgson JB, Chinwalla AT, Cliften PF, Clifton SW, Delehaunty KD, Fronick C, Fulton RS, Graves TA, Kremitzki C, Layman D, Magrini V, McPherson JD, Miner TL, Minx P, Nash WE, Nhan MN, Nelson JO, Oddy LG, Pohl CS, Randall-Maher J, Smith SM, Wallis JW, Yang SP, Romanov MN, Rondelli CM, Paton B, Smith J, Morrice D, Daniels L, Tempest HG, Robertson L, Masabanda JS, Griffin DK, Vignal A, Fillon V, Jacobbson L, Kerje S, Andersson L, Crooijmans RP, Aerts J, van der Poel JJ, Ellegren H, Caldwell RB, Hubbard SJ, Grafham DV, Kierzek AM, McLaren SR, Overton IM, Arakawa H, Beattie KJ, Bezzubov Y, Boardman PE, Bonfield JK, Croning MD, 
Davies RM, Francis MD, Humphray SJ, Scott CE, Taylor RG, Tickle C, Brown WR, Rogers J, Buerstedde JM, Wilson SA, Stubbs L, Ovcharenko I, Gordon L, Lucas S, Miller MM, Inoko H, Shiina T, Kaufman J, Salomonsen J, Skjoedt K, Wong GK, Wang J, Liu B, Yu J, Yang H, Nefedov M, Koriabine M, Dejong PJ, Goodstadt L, Webber C, Dickens NJ, Letunic I, Suyama M, Torrents D, von Mering C, Zdobnov EM, Makova K, Nekrutenko A, Elnitski L, Eswara P, King DC, Yang S, Tyekucheva S, Radakrishnan A, Harris RS, Chiaromonte F, Taylor J, He J, Rijnkels M, GriffithsJones S, Ureta-Vidal A, Hoffman MM, Severin J, Searle SM, Law AS, Speed D, Waddington D, Cheng Z, Tuzun E, Eichler E, Bao Z, Flicek P, Shteynberg DD, Brent MR, Bye JM, Huckle EJ, Chatterji S, Dewey C, Pachter L, Kouranov A, Mourelatos Z, Hatzigeorgiou AG, Paterson AH, Ivarie R, Brandstrom M, Axelsson E, Backstrom N, Berlin S, Webster MT, Pourquie O, Reymond A, Ucla C, Antonarakis SE, Long M, Emerson JJ, Betran E, Dupanloup I, Kaessmann H, Hinrichs AS, Bejerano G, Furey TS, Harte RA, Raney B, Siepel A, Kent WJ, Haussler D, Eyras E, Castelo R, Abril JF, Castellano S, Camara F, Parra G, Guigo R, Bourque G, Tesler G, Pevzner PA, Smit A, Fulton LA, Mardis ER, Wilson RK. Sequence and comparative analysis of the chicken genome provide unique perspectives on vertebrate evolution. Nature 2004;432(7018):695-716. [PubMed: 15592404] 
A

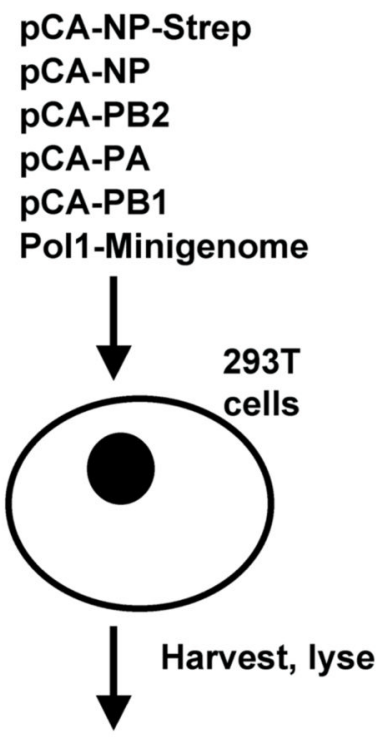

Strep-purification
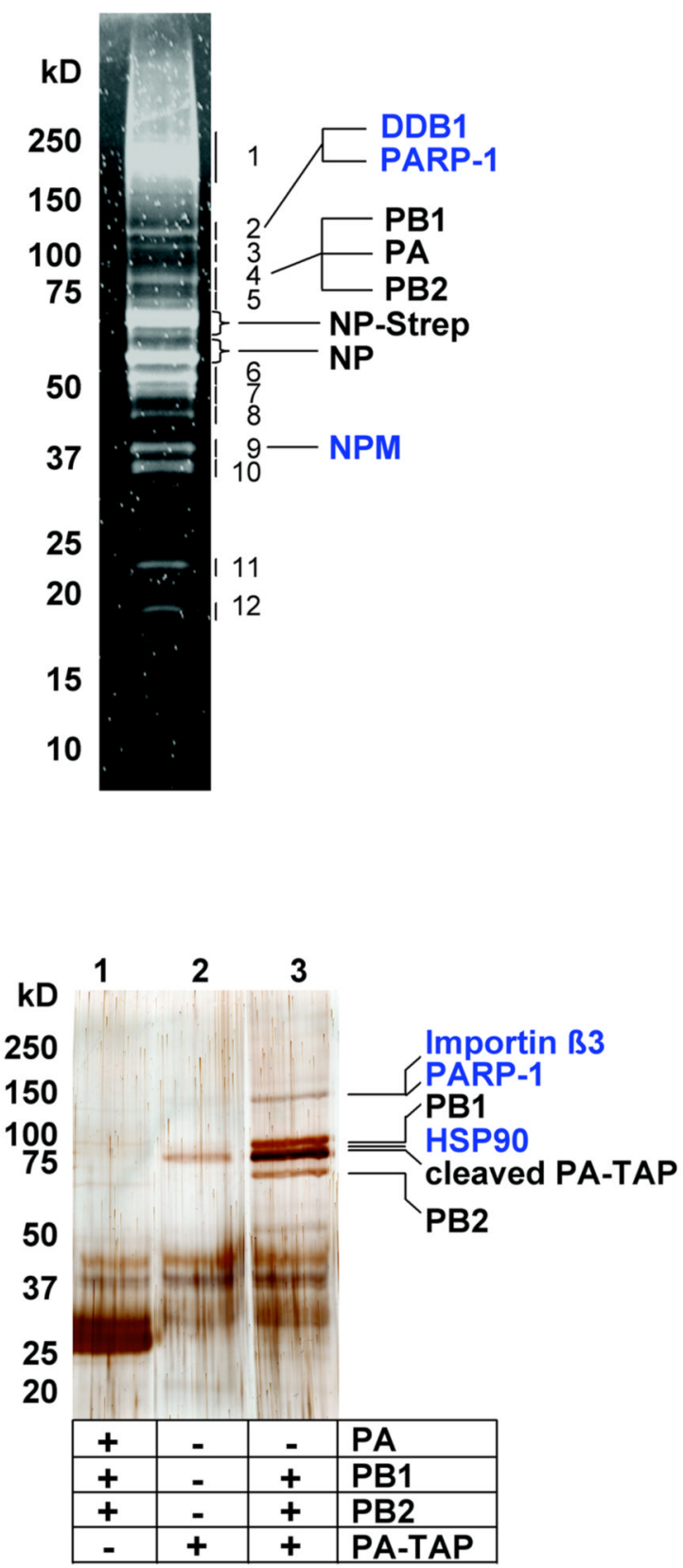

TAP-purification

Fig. 1. Purification of cellular interaction partners of influenza virus RNP and polymerasecomplex A, Purification of NP-Strep from cells transfected with viral RNP components. Left panel: to reconstitute viral RNPs that can be purified by the Strep procedure, 293T cells were transfected with the indicated expression plasmids (pCA) encoding the viral nucleoprotein fused Cterminally fused to STREP-tag (NP-Strep), untagged NP and the polymerase subunits PA, PB1 and $\mathrm{PB} 2$ and a plasmid expressing influenza virus minigenome transcripts under the control of a polymerase-I (PolI) promoter. After 24 hours, when viral RNA replication and transcription had occurred (data not shown), a cell extract was prepared for Strep purification. Right panel: Native NP-Strep protein complex bound to Streptactin-beads was released by desthiobiotin, separated on a denaturing linear 4-20\% SDS-PAGE and finally visualized by 
staining with Sypro-Ruby. Numbers on the right side indicate gel slices used for tryptic digestion with trypsin and analysis by MS. Position of NP-Strep and NP as well as PARP-1, DDB1 and NPM are indicated.

B, Purification of the influenza virus polymerase complex. Left panel: Cartoon showing the procedure used to purify the viral polymerase complex using TAP-tagged PA. For this purpose, 293T cell were transiently transfected with the indicated expression constructs encoding for the TAP-tagged PA and untagged PB1 and PB2. After 24 hours, the native polymerase complex was purified by the TAP-method (right panel, lane 3). Right panel: HEK 293 T cells were transfected with plasmids encoding the indicated polymerase subunits in untagged or TAPtagged form. Twenty-four hours after transfection a cell extract was prepared for the TAPpurification. Protein complexes were first bound to IgG-sepharose, released by cleavage with tobacco etch virus protease, and subsequently bound to calmodulin-binding agarose beads. In a final step bound protein complexes were eluted with $\mathrm{Ca} 2+$, concentrated, separated by $4-$ $20 \%$ SDS-PAGE and visualized by silver staining. The position and names of proteins identified by mass spectrometry are indicated. 


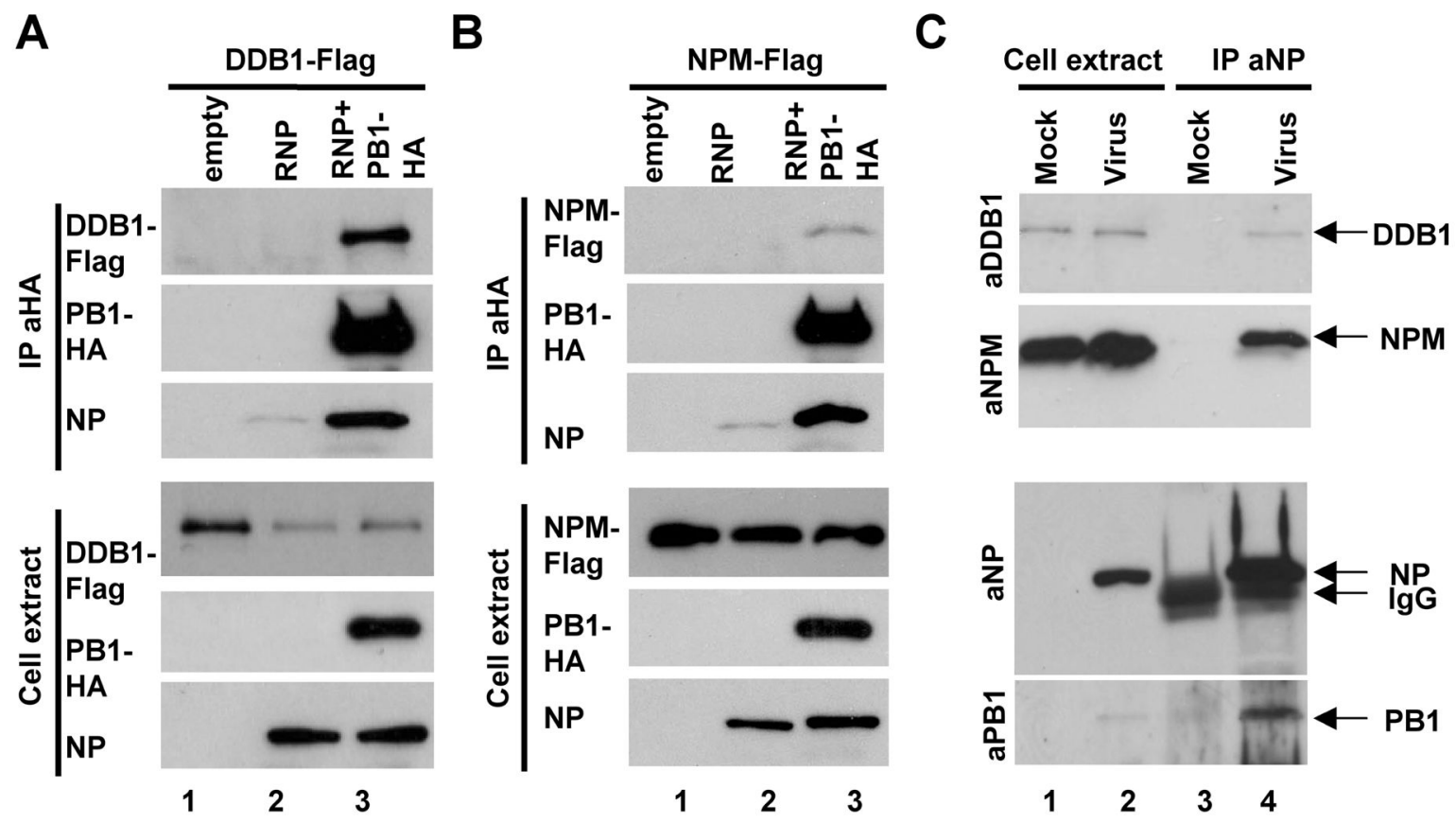

Fig. 2. Interaction of NPM and DDB1 with viral RNP in transfected cells and in infected cells A, To confirm the interaction between DDB 1 and reconstituted viral RNP by coimmunoprecipition experiments, 293T cells were transfected with expression plasmids encoding DDB1-Flag and the components of the polymerase complex (PB1-HA, PB2, PA, NP) and a plasmid expressing an influenza virus minigenome (lane 3). Cell extract was prepared 24 hours post transfection and used for immunprecipitation (IP) with HA-specific antibodies. The presence of DDB1-Flag, PB1-HA and NP in the precipitates (upper panels) as well as in the cytoplasmic extracts (lower panels) was analyzed by Western blotting using HA-, Flag and NP-specific antibodies. In control experiments only DDB1-Flag was transfected in 293 T cells (lane 1) or all plasmids as in lane 3 with the exception that a plasmid expressing PB1 and not PB1-HA was used (lane 2). Approximately $3 \%$ of total cell extract used for IP was loaded.

B, Co-immunoprecipitation experiments as in A expressing NPM-Flag.

$\mathrm{C}$, To test whether endogenous NPM and DDB1 interact with influenza RNPs during viral infection, MDCK cells were infected with influenza A/WSN/33 virus at a MOI of 0.5 or mock infected. Immunoprecipitation was carried out with total cell extract 12 hours post infection and anti-NP-specific antibodies. Precipitated cell extracts were analyzed by Western blot using antibodies specific for NPM $(\alpha \mathrm{NPM}), \mathrm{NP}(\alpha \mathrm{NP})$ or PB1 $(\alpha \mathrm{PB} 1)$. Arrows indicate positions of NPM, NP, IgG heavy chain and PB1. Approximately $3 \%$ of total cell extract used for IP was loaded. 

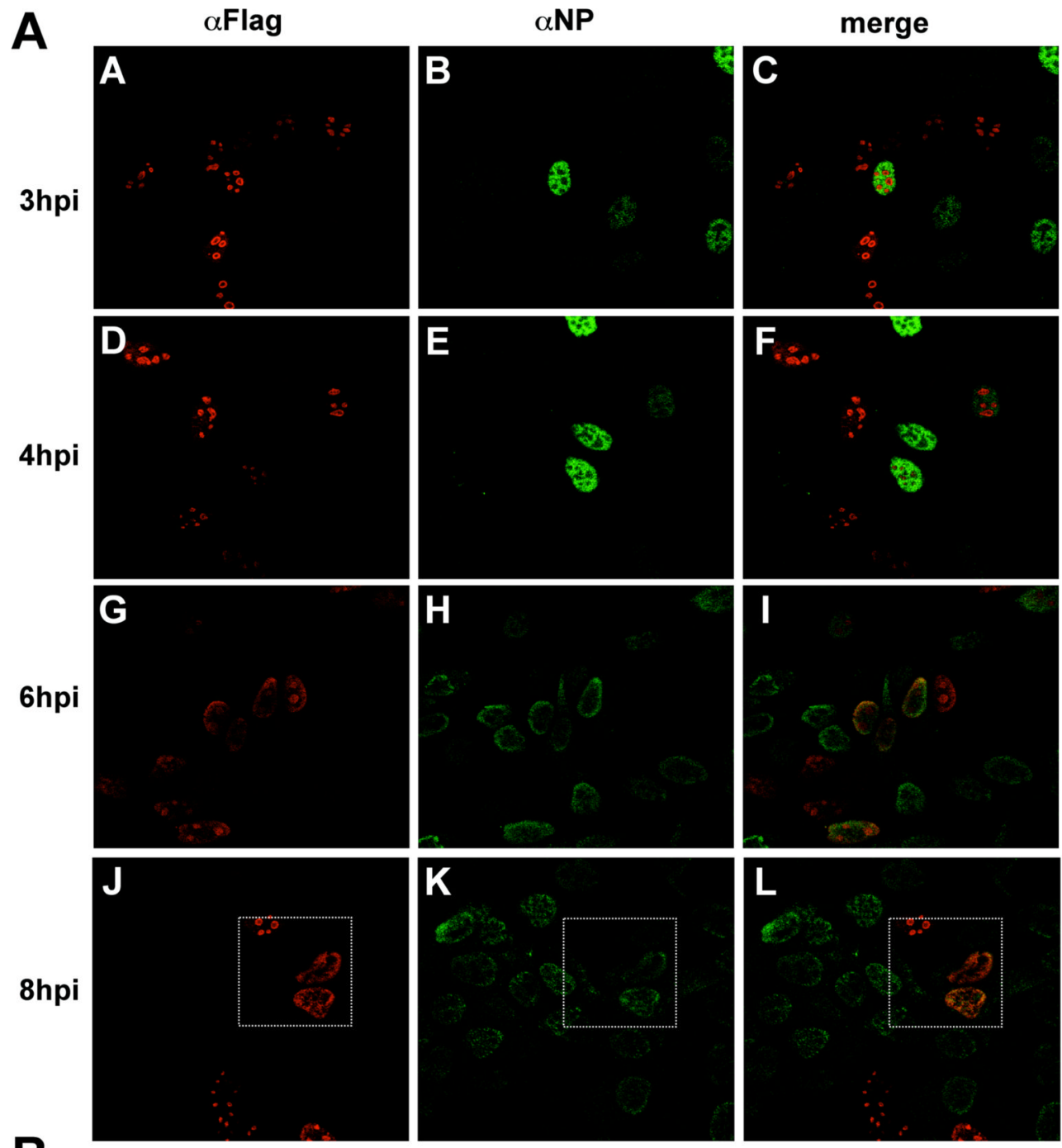

B
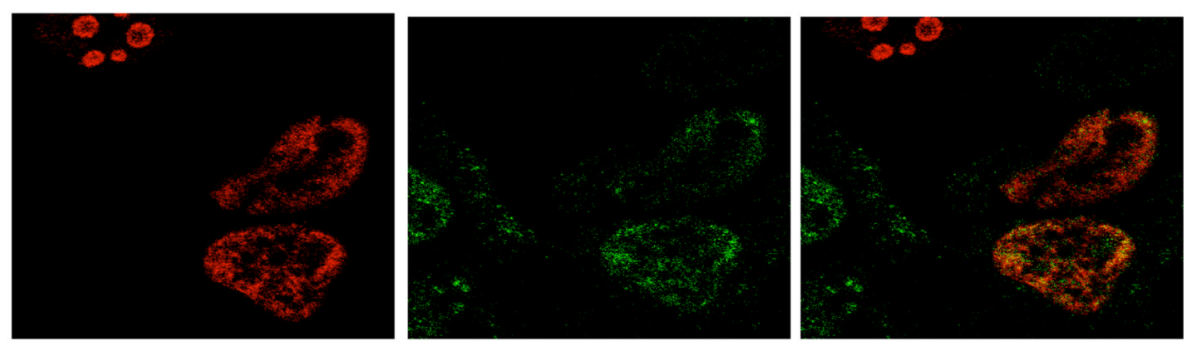

Fig. 3. Relocalization of NPM-Flag after influenza virus infection

A, MDCK cells were transiently transfected with an expression plasmid coding for NPM-Flag and subsequently infected with influenza A/WSN/33 virus (MOI 0.5). At the indicated time points post infection, cells were processed for immunofluorescence analysis using a Flagspecific monoclonal antibody to detect NMP-Flag and a rabbit polyclonal anti-NP-specific antiserum to visualize NP.

B Magnification of the dotted region shown in A, panels J-L. Note that early in infection (34h) as well as in non-infected cells the majority of NPM-Flag localizes in the nucleolus, whereas late in infection (8h) NPM-Flag colocalizes with NP in the nucleus. 


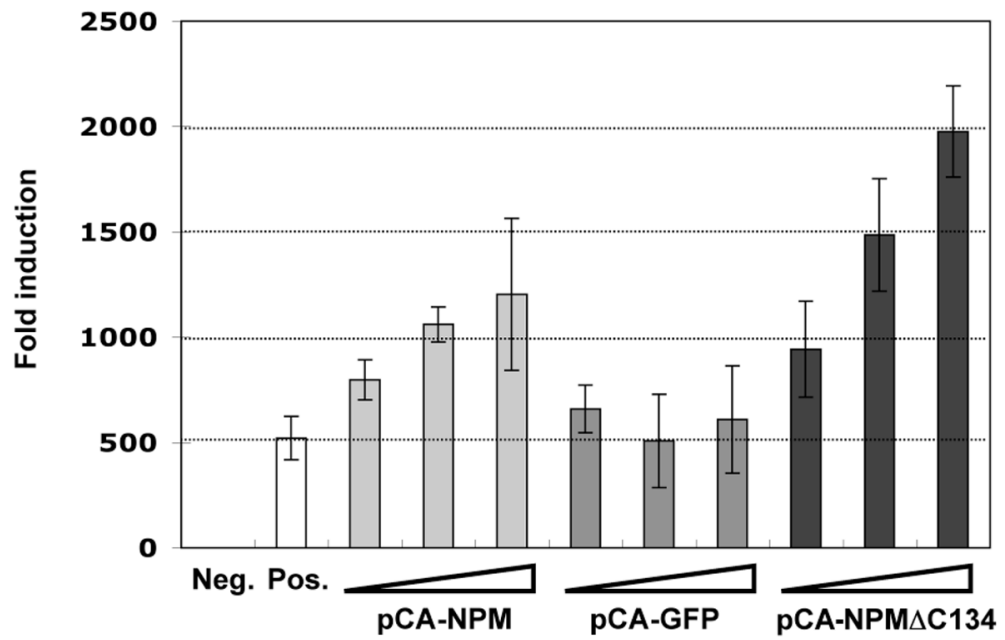

Fig. 4. Expression of NPM increases the influenza virus polymerase activity HEK 293 T cells were transiently transfected with PB1-, PB2-, NP-, PA-expression plasmids and a PolI-Minigenome plasmid coding for the reporter protein firefly luciferase to monitor viral polymerase activity. The transfection mixture also contained a plasmid constitutively expressing renilla luciferase, which served to normalize variation in transfection efficiency. The firefly luciferase activity was determined 24 hour post transfection and normalized to the renilla values. Neg.: transfection reactions without PB2. Pos.: complete set of plasmids. The transfections with increasing amounts of plasmids (100, 500 and $1000 \mathrm{ng}$ ) encoding NPM, GFP and a NPM mutant lacking the C-terminal 134 amino acids are indicated. The error bars represent standard deviations. 
Table 1

Cellular proteins identified by Strep purification (vRNP components)

\begin{tabular}{|c|c|c|c|c|}
\hline Band No & $\begin{array}{c}\% \text { coverage aa } \\
\text { (mass) }\end{array}$ & Hits & Acc. No & Protein name \\
\hline 1 & $\begin{array}{l}1.0(1.0) \\
3.5(3.3)\end{array}$ & $\begin{array}{l}1 \\
2\end{array}$ & $\begin{array}{l}\text { Q13085 } \\
\text { Q16531 }\end{array}$ & $\begin{array}{l}\text { Acetyl-CoA carboxylase } 1 \\
\text { Transcription intermediary factor 1-beta }\end{array}$ \\
\hline 2 & $\begin{array}{c}7.5(7.5) \\
32.8(32.6) \\
9(8.5)\end{array}$ & $\begin{array}{c}4 \\
31 \\
3\end{array}$ & $\begin{array}{l}\text { Q13263 } \\
\text { P09874 } \\
\text { Q14694 }\end{array}$ & $\begin{array}{l}\text { DNA damage binding protein } 1 \text { DDB1 } \\
\text { Poly [ADP-ribose] polymerase-1 PARP-1 } \\
\text { Ubiquitin carboxyl-terminal hydrolase } 10\end{array}$ \\
\hline 3 & $\begin{array}{c}10.2(10.7) \\
4.4(4.7) \\
11.6(11.8) \\
11.6(11.8)\end{array}$ & $\begin{array}{l}4 \\
3 \\
3 \\
1\end{array}$ & $\begin{array}{l}\text { P19338 } \\
\text { P56192 } \\
\text { Q9BV09 } \\
\text { P09874 }\end{array}$ & $\begin{array}{l}\text { Nucleolin (Protein C23) } \\
\text { Methionyl-tRNA synthetase } \\
\text { Membrane component, chromosome 11, surface marker } 1 \\
\text { Poly [ADP-ribose] polymerase-1 }\end{array}$ \\
\hline 4 & $\begin{aligned} & 8.9(9.1) \\
& 10.0(10.2) \\
& 2.2(2.3)\end{aligned}$ & $\begin{array}{l}7 \\
3 \\
1\end{array}$ & $\begin{array}{l}\text { P13010 } \\
\text { Q01844 } \\
\text { Q12906 }\end{array}$ & $\begin{array}{l}\text { ATP-dependent DMA helicase II, } 80 \mathrm{kDa} \text { subunit } \\
\text { RNA-binding protein EWS (EWS oncogene) } \\
\text { Interleukin enhancer-binding factor } 3\end{array}$ \\
\hline 5 & $\begin{aligned} 12.8(12.6) \\
35.1(35.6) \\
12.8(12.5) \\
15.9(15.7) \\
1.4(1.4) \\
3.8(3.7) \\
11.1(11.0) \\
8.8(8.8)\end{aligned}$ & $\begin{array}{c}6 \\
24 \\
5 \\
9 \\
1 \\
1 \\
4 \\
4\end{array}$ & $\begin{array}{l}\text { P08107 } \\
\text { P11142 } \\
\text { P12956 } \\
\text { P11940 } \\
\text { P52272 } \\
\text { Q9UHB9 } \\
\text { Q15046 } \\
\text { Q92841 }\end{array}$ & $\begin{array}{l}\text { Heat shock } 70 \mathrm{kDa} \text { protein } 1 \text { (HSP70.1) (HSP70-1/-2) } \\
\text { Heat shock cognate } 71 \mathrm{kDa} \text { protein } \\
\text { ATP-dependent DMA helicase II, 70 kDa subunit } \\
\text { Polyadenylate-binding protein 1) (PABP 1) } \\
\text { Heterogeneous nuclear ribonucleoprotein M (hnRNP M) } \\
\text { Signal recognition particle } 68 \mathrm{kDa} \text { protein } \\
\text { Lysyl-tRNA synthetase } \\
\text { Probable RNA-dependent helicase p72 }\end{array}$ \\
\hline 6 & $\begin{aligned} 18.6(18.8) \\
5.0(5.5) \\
29.9(29.6) \\
6.7(6.1) \\
3.5(3.7) \\
26.8(26.6) \\
35.1(34.8) \\
43.5(43.1)\end{aligned}$ & $\begin{array}{c}9 \\
2 \\
11 \\
3 \\
1 \\
8 \\
15 \\
18\end{array}$ & $\begin{array}{l}\text { P04720 } \\
\text { P11182 } \\
\text { Q13885 } \\
\text { Q9Y230 } \\
\text { Q13838 } \\
\text { P05209 } \\
\text { P05217 } \\
\text { P05218 }\end{array}$ & $\begin{array}{l}\text { Elongation factor } 1 \text {-alpha } 1 \\
\text { Lipoamide acyltransferase component } \\
\text { Beta tubulin (Tubulin, beta polypeptide) } \\
\text { RuvB-like } 2 \\
\text { Spliceosome RNA helicase BAT1 } \\
\text { Tubulin alpha-1 chain } \\
\text { Tubulin beta-2 chain } \\
\text { Tubulin beta- } 5 \text { chain }\end{array}$ \\
\hline 7 & $\begin{array}{l}22.1(21.8) \\
10.4(10.4)\end{array}$ & $\begin{array}{l}6 \\
3\end{array}$ & $\begin{array}{l}\text { P05218 } \\
\text { P05209 }\end{array}$ & $\begin{array}{l}\text { Tubulin beta- } 5 \text { chain } \\
\text { Tubulin alpha- } 1 \text { chain }\end{array}$ \\
\hline 8 & $\begin{aligned} 12.0(11.8) \\
3.8(3.3) \\
30.9(30.6) \\
21.3(20.7)\end{aligned}$ & $\begin{array}{c}3 \\
1 \\
14 \\
8\end{array}$ & $\begin{array}{l}\text { P02570 } \\
\text { P52292 } \\
\text { P12268 } \\
\text { P08670 }\end{array}$ & $\begin{array}{l}\text { Actin, cytoplasmic } 1 \text { (Beta-actin) } \\
\text { Importin alpha-2 } \\
\text { Inosine-5'-monophosphate dehydrogenase } 2 \\
\text { Vimentin }\end{array}$ \\
\hline 9 & $16.0(15.9)$ & 3 & P06748 & Nucleophosmin(NPM) \\
\hline 10 & $\begin{array}{l}26.4(24.7) \\
53.6(52.8) \\
9.7(10.1)\end{array}$ & $\begin{array}{c}7 \\
17 \\
2\end{array}$ & $\begin{array}{l}\text { P46777 } \\
\text { P05388 } \\
\text { P09651 }\end{array}$ & $\begin{array}{l}\text { 60S ribosomal protein L5 } \\
60 \mathrm{~S} \text { acidic ribosomal protein P0 } \\
\text { Heterogeneous nuclear ribonucleoprotein A1 }\end{array}$ \\
\hline 11 & $\begin{array}{l}38.5(38.4) \\
23.0(22.0) \\
21.3(20.3)\end{array}$ & $\begin{array}{l}9 \\
5 \\
3\end{array}$ & $\begin{array}{l}\text { P32969 } \\
\text { P46782 } \\
\text { P23152 }\end{array}$ & $\begin{array}{l}\text { 60S ribosomal protein L9 } \\
\text { 40S ribosomal protein S5 } \\
\text { Splicing factor SFR3 }\end{array}$ \\
\hline 12 & $\begin{array}{c}20.8(20.3) \\
6.4(6.3) \\
19.6(19.4)\end{array}$ & $\begin{array}{l}2 \\
1 \\
2\end{array}$ & $\begin{array}{l}\text { P32969 } \\
\text { P46782 } \\
\text { P23821 }\end{array}$ & $\begin{array}{l}\text { 60S ribosomal protein L9 } \\
40 \text { S ribosomal protein S5 } \\
40 \text { S ribosomal protein S7 (S8) }\end{array}$ \\
\hline
\end{tabular}

Acc No.: Swissprot/TrEMBL accession number, peptide probabilities were calculated with Protein Prophet with a cut off value of 0.9 (Keller et al., 2002), the column "hits" provides the number of unique peptides that were identified from each protein with a PeptideProphet score above 0.9 (Keller et al., 2002). The column "coverage" indicates the percentage of amino acids and molecular mass (in brackets) that are covered by the identified peptides. Orange: published interaction partners (Supplemental Table 1); Blue: Proteins further characterized in this study. 
Table 2

Cellular proteins identified by the TAP purification of the viral polymerase complex

\begin{tabular}{ccll} 
\% coverage aa (mass) & Hits & Acc. No & Protein name \\
\hline $7.4(7.1)$ & 6 & O00410 & Importin beta-3 \\
$3.8(3.7)$ & 3 & P09874 & Poly [ADP-ribose] polymerase-1 \\
$10.2(10.4)$ & 5 & P08238 & Heat shock protein HSP 90R
\end{tabular}

Acc No.: Swissprot/TrEMBL accession number, peptide probabilities were calculated with Protein Prophet with a cut off value of 0.9 (Keller et al., 2002), the column "hits" provides the number of unique peptides that were identified from each protein with a PeptideProphet score above 0.9 (Keller et al., 2002). The column "coverage" indicates the percentage of amino acids and molecular mass (in brackets) that are covered by the identified peptides. Orange: published interaction partners (Supplemental Table 1). 